\title{
A leitura de textos literários no ensino de história escolar: entrelaçando percursos metodológicos para o trato com os conceitos de tempo e espaço
}

\section{Reading literary texts in teaching school history: intertwining courses methodology for dealing with time and space concepts}

Maria Aparecida Leopoldino*

\section{Resumo}

O artigo destaca a importância da literatura infantil para o ensino de História escolar. Partindo das produções já elaboradas sobre os nexos entre história e literatura, seu intuito é pensar algumas facetas dessa questão metodológica destacando como a literatura infantil, concebida em sua potencialidade como narrativa historiográfica e, ao mesmo tempo, como objeto possível ou necessário da compreensão de narrativas sobre o passado, pode ajudar no esforço de significar os conceitos de tempo e espaço no ensino fundamental.

Palavras-chave: ensino de história; literatura infantil; metodologia do ensino.

\section{Abstract}

The article highlights the importance of children's literature for teaching school history. Starting from the productions already produced about the links between history and literature, thinks some facets of this methodological issue highlighting how children's literature, thought to its potential as a historiographical narrative and at the same time as possible or necessary object of understanding of narratives about the past can help in the effort to signify the concepts of time and space in elementary school.

Keywords: history teaching; children's literature; teaching methodology.

No Brasil, desde o final dos anos 1980, as pesquisas no campo do ensino de História vêm mostrando como é desafiador, para os professores que trabalham com os anos iniciais do ensino fundamental, não somente desnaturalizar o herói e fazer a crítica das datas comemorativas, mas, sobretudo, elaborar

\footnotetext{
* Doutora em Educação (PUC-SP). Professora associada do Departamento de Teoria e Prática da Educação da Universidade Estadual de Maringá. Maringá,PR, Brasil.leopoldino.mariaaparecida@ yahoo.com.br
} 
perspectivas pedagógicas com a preocupação em trabalhar centralmente os conceitos de tempo e espaço.

Tal problemática tem sido pensada sob diferentes perspectivas metodológicas. Entre elas, os debates sobre as contribuições da literatura, para se pensar tais conceitos, aparecem no cenário nacional particularmente interessados em "refletir sobre conexões entre literatura e a história no processo educativo", uma vez que, reconhecida a diferença entre os gêneros textuais, compreende-se que "estão associadas ao desenvolvimento da leitura, da escrita, à percepção dos múltiplos sentidos agregados aos vocabulários, à formação ética e estética, à ampliação do universo cultural e da compreensão do mundo" (Zamboni; Fonseca, 2010, p.341).

Considerando essas relações estabelecidas entre aprendizagem da leitura e a literatura infantil, Maria do Rosário Longo Mortatti (2014) observa que o ensino da literatura é um "momento didático-pedagógico do ensino escolar formal, intencional e organizado, que, por sua vez, integra o processo de formação (integral), com a finalidade de contribuir para o processo de emancipação humana". Na expressão "ensino da literatura" ter-se-ia, simultaneamente, "a indicação de objeto de ensino escolar e de um momento específico de ensino e aprendizagem, que integra o processo educativo e que se refere ao lugar e à contribuição da literatura para a educação, por meio do ensino" (Mortatti, 2014, p.30).

Nesse aspecto é que se percebe o entrelaçar dos percursos metodológicos no ensino de história escolar, quando o professor toma textos literários para uma leitura histórica da realidade social vivida. Isso porque o uso da literatura no ensino de História, além de ser compreendido como uma diversificação de fontes para ensinar história, possibilita mediar a compreensão de um conjunto de contextos sociais e históricos em sala de aula.

A historiografia, por sua vez, se aproxima, enquanto linguagem, da literatura e, por se tratar de linguagens variadas, cada uma delas guarda distintos níveis de aproximação com a realidade. De forma que ambas as narrativas trocam sinais, se aproximam ou se distanciam na busca por compreender elementos de historicidade em determinado espaço social.

Vários trabalhos voltados ao ensino de História já trataram de como utilizar obras literárias nas aulas como "subsídio para construir conhecimento histórico”. Eles indicam que romances, contos, crônicas e tantas outras 
expressões literárias podem ser "objetos desafiadores e prazerosos para o professor que visa diversificar sua prática cotidiana de ensino" (Abud; Melo Silva; Alves, 2010, p.41).

Trata-se, certamente, de um ponto muito importante relacionar história e literatura no ensino escolar como indicam os estudos, mas, ao mesmo tempo, trata-se também de uma difícil tarefa elaborar proposta didático-pedagógica, uma vez que ao se discutir conceitos básicos do campo de produção de conhecimentos históricos exige-se que se estabeleça um diálogo muito aproximado com a prática historiográfica e o campo de trabalho do historiador, mesmo que se tenha a literatura como fonte.

Nesse percurso, compreende-se que, além de tratar dos conceitos de tempo e espaço, é igualmente importante reconhecer as tendências historiográficas atuais e sua ampliação do conceito de documento e fonte histórica para situar a literatura nesse universo. Realizar uma análise nesse sentido requer esforços que transbordam o espaço deste artigo. Por isso, o intento aqui é, partindo das produções já elaboradas sobre os nexos entre história e literatura, pensar algumas facetas dessa questão metodológica, destacando como a literatura infantil, pensada em sua potencialidade como narrativa historiográfica e, ao mesmo tempo, como objeto possível ou necessário da compreensão de narrativas sobre o passado, pode ajudar no esforço de significar os conceitos de tempo e espaço no ensino fundamental.

Trata-se de entender este trabalho, portanto, como uma tentativa de indicar uma possibilidade de uso da linguagem escrita e iconográfica presente nos livros de literatura infantil para ensinar conceitos fundantes da produção de conhecimentos históricos.

Entrelaçar caminhos metodológicos nesse sentido significa buscar em textos literários um acesso a formas de se representar e expressar o mundo social, almejando-se com isso problematizar, por intermédio das linguagens, questões relativas a conceitos temporais e espaciais da vida prática em sociedade. Isso porque se espera que o ensino de História desde os anos iniciais do fundamental possa ajudar o aluno a formular conceitos de tempo e espaço a partir de sua vivência cotidiana e das relações sociais vividas, habilitando-o a perceber passagem do tempo e suas diferentes dimensões.

Nesse sentido, este trabalho, fruto de uma experiência desenvolvida na formação de professores, se alinha à perspectiva do "educar para a compreensão do 
tempo". Ou seja, busca problematizar o texto literário e assim compreender os modos como ele pode ajudar com "a experiência com o tempo - que advém da passagem dos eventos da vida humana e das práticas de sociabilidade a que os indivíduos são expostos desde a infância” (Oliveira; Miranda, 2010, p.273). Para lidar com essa perspectiva, elegeu-se o livro de Anna Flora de Camargo Coelho, um paradidático da literatura infantil produzido em fins da década de 1980 pela editora Salamandra.

Por intermédio do livro Em volta do quarteirão, de autoria de Anna Flora, o artigo sugere que a significação da literatura infantil não está nela mesma, mas nas possibilidades de interpretação de sua interação com a realidade sociocultural. Tomar o livro de literatura infantil como fonte e objeto para ensinar conceitos de história requer o reconhecimento de que tanto as narrativas literárias quanto a historiográfica respondem a uma demanda social por representações que atuam no sentido da constituição de identidades individuais e coletivas de determinada sociedade, no âmbito escolar.

\section{LITERATURA INFANTIL: OBJETO E FONTE PARA O ENSINO DE HISTÓRIA ESCOLAR}

A Literatura Infantil é, antes de tudo, literatura, ou melhor, é arte: fenômeno de criatividade que representa o Mundo, o Homem, a Vida, através da palavra. Funde os sonhos e a vida prática; o imaginário e o real; os ideais e sua possível/impossivel realização.

Cagneti, 1996, p.7

Roger Chartier, ao se dedicar à análise das relações existentes entre gêneros textuais, formas editoriais e práticas de leitura, tem contribuído para a constituição de um instrumental de análise de livros escolares. É dele a indicação de que é "necessário compreender que nossa relação contemporânea com as obras e os gêneros não pode ser considerada nem como invariante nem como universal" (Chartier, 1999, p.197). O seja, em vez de partir da de um vínculo pretensamente estabilizado entre obra e leitor, o historiador deve romper com "a atitude espontânea que supõe que todos os textos, todas as obras, todos os gêneros, foram compostos, publicados, lidos e recebidos segundo os critérios que caracterizam nossa própria relação com o escrito” (p.197). 
Pensar a Literatura Infantil nesses termos é reconhecer os efeitos produzidos pelas formas dos discursos sobre a criação de seu sentido de texto literário. A Literatura Infantil, praticada desde o século XVIII, foi pautada em seu desenvolvimento por um pacto com as instituições envolvidas com a educação da criança. Tendo isso em mente, pode-se definir com maior segurança os tipos de livros que mais agradam aos pequenos leitores: histórias fabulosas, contos de aventuras, lendas e outros que retratem o cotidiano da criança. O livro infantil é criado com intenção claramente pedagógica - o uso escolar - e os livros de leitura usados nas escolas foram conscienciosos na produção de uma literatura específica para crianças.

A importância da instituição escolar para o desenvolvimento da Literatura Infantil deveu-se ao seu fortalecimento enquanto instituição e às campanhas de escolaridade próprias do período, fatos estreitamente relacionados às grandes mudanças processadas na vida cultural e política no decorrer do século XIX. De acordo com Arroyo (1968), “os livros de histórias infantis eram usados como 'pretexto' para ensinar outros pontos da matéria, tornando a escola destinatária privilegiada da produção desses textos”.

Com a preocupação em transmitir uma ideia de país em modernização, muitos valores dessa sociedade foram mediados por livros infantis. Assim, boa parte dos livros infantis desta época possuíam características em comum, centradas na ideia de civismo como missão e buscando por isso mesmo inculcar patriotismo nas crianças. São narrativas que surgem como resultado de um vasto complexo cultural que marcou as manifestações político-populares, conforme apontou Cecília Meireles (1979, p.66-69): “em todas as latitudes, e desde sempre, é a Literatura Tradicional a primeira a instalar-se na memória da criança. Ela representa o seu primeiro livro, antes mesmo da alfabetização, e o único, nos grupos sociais carecidos de letras".

Nesse sentido, ouvir ou ler histórias iniciava a criança no processo de construção de linguagem, ideias, valores e sentimentos que contribuíam com sua formação cultural. Tal observação denota a importância de se repensar o texto literário isolado em seu gênero textual para reconhecê-lo como pertencente ao conjunto de uma cultura escolar, com diálogo e inserção em debates que integram uma conformação pedagógica complexa, constituída por uma ordem literária que cria, difunde e dá sustentação aos programas escolares e 
às práticas que lhe fornecem temáticas e estéticas fundamentais, assim como o ensino de História.

É importante considerar, por isso, o sentido dos textos como o resultado de uma negociação ou transações entre a invenção literária e os discursos ou práticas do mundo social que buscam, ao mesmo tempo, os materiais e matrizes da criação estética e as condições de sua possível compreensão (Meireles, 1979).

O entendimento do livro como um espaço de relações pedagógicas não permite, pois, que se fale sobre a narrativa, o "texto", em abstrato, como existente fora dos objetos escritos que permitem sua leitura, antes fazem pensar em um objeto que resulta de um conjunto de elementos que compõem o livro, como a letra e a imagem. Além desses elementos formadores da materialidade do livro, há de se considerar, ainda, o processo de construção de sentidos - pelo leitor tendo em mente a relação mútua entre as diferentes linguagens (imagética, narrativa) que compõem o texto literário. No caso, a literatura infantil passa a ser vista, na observação de Abramovich (1991 p.17), como "uma possibilidade de descobrir o mundo imenso dos conflitos, dos impasses, das soluções que todos vivemos e atravessamos", por meio das questões postas pela história escolar.

Compreendida dessa maneira, a Literatura Infantil responde a dramas humanos e socioculturais, e, assim, às representações da realidade tal qual ela é percebida e interpretada pelos produtores da arte e do conhecimento. Metodologicamente, é nessa relação que o processo de construção de sentidos se realiza por meio das possibilidades de interação entre as duas linguagens que compõem o texto e produzem leituras diversas. Nesse cruzamento entre a História e a Literatura, o historiador se vale do texto literário "não mais como uma ilustração do contexto em estudo, como um dado a mais, para compor uma paisagem dada". É a História que formula questões, enquanto a Literatura "opera como fonte", de forma que a Literatura ocupa "a função de traço, que se transforma em documento e que passa a responder às questões formuladas pelo historiador" (Pesavento, 2005, p.82).

Tempo e história se relacionam na investigação e no ensino do tempo histórico. É possível, por meio do ensino escolar, como tem mostrado tais pesquisas, que as crianças em idade inicial do processo de alfabetização se apropriem desse conceito ao longo do ensino e da aprendizagem da História. É nesse quesito que a Literatura Infantil faz uma especial contribuição. Por intermédio das falas dos atores, das suas ações, da narrativa do autor, as crianças podem perceber que $o$ 
tempo passa no decorrer da história. Podem notar que tempo e espaço são indissociáveis e que não existe uma única temporalidade. A percepção do tempo é "una gran diversidad de experiencias y de representaciones" (Blanch; Fernández, 2010, p.282), que marca a linguagem literária.

Considerando-se que, como já afirmaram (Blanch; Fernández, 2010, p.282), no ensino escolar estuda-se o tempo, entre outros motivos, para "poder decir qué passaba em el mundo cuando yo nací, qué película hacían em los cines, qué canción se escuchaba, qué conflictos existían o quién mandaba, qué era noticia o cómo era mi ciudad", ao se considerar a Literatura Infantil no trato pedagógico com conceitos de tempo e espaço espera-se avançar o terreno da narrativa literária e destacar as práticas socioculturais e suas temporalidades, a fim de se compreender as mudanças, permanências e continuidades das práticas em que os atores sociais - personagens do enredo - estão envolvidos.

Nessa concepção, o conceito de tempo histórico enquanto movimento e pluralidade, que não se esgota na brevidade dos dias, dos meses, dos anos e dos séculos, é que será enfatizado. Entende-se que essa é uma possibilidade de ver a literatura como objeto e fonte para um diálogo entre a história ensinada e a historicidade que se lê na narrativa literária.

EM VOLTA DO QUARTEIRÃO: REPRESENTAÇÕES DA VIDA COTIDIANA E HISTÓRIA DO LUGAR

O que a criança (e na lembrança esmaecida, o homem) encontra nas dobras dos velhos vestidos, nas quais ela se comprimia ao agarrar-se às saias da mãe - eis o que essas páginas devem conter.

Benjamin, 2006

Nas práticas escolares contemporâneas, as crianças em fase de alfabetização e letramento iniciam seu processo de aprendizado da leitura a partir do contato com impressos, momento em que a Literatura Infantil aparece como um instrumento central. A presença das linguagens verbal e visual contribui para a aprendizagem do universo escrito prevendo espaços de atuação dos pequenos leitores na obra. Ao narrar uma história, a literatura trabalha com temporalidades. São aspectos de duração, sequências cronológicas, relações entre passado e presente, enfim, uma linguagem temporal que permite que as 
crianças construam noções de temporalidades e espacialidades na prática de leitura que organiza o conteúdo escolar.

No ensino de História, em especial nos anos iniciais do fundamental, texto, imagem, oralidade e representações tornam-se objeto de estudo para a apropriação da leitura e da escrita pela criança. Suportes importantes, no ensino de leituras sobre o passado ou mesmo para o trato pedagógico com conceitos historiográficos, eles se tornam fonte e objeto para os desafios metodológicos característicos do trabalho escolar com os saberes históricos.

A presença da história social como fundamento para o ensino de História escolar, por sua vez, tem permitido ampliar a perspectiva de se trabalhar com os conceitos de experiência e representações nas salas de aula. No que toca a considerações metodológicas, quando se almeja tratar a realidade social pedagogicamente, o tempo passado não pode mais ser estudado como algo que passou ou deixou de existir; torna-se importante na verdade abordá-lo como uma constante problematização do vivido. Realidade vivida numa dada relação entre variados atores sociais e, por isso, experienciada em múltiplas temporalidades. Quais temporalidades podem ser percebidas?

Ao se explorar tais linguagens, possibilita-se ao professor e aos alunos participarem da construção de sentidos dos elementos presentes na narrativa e nas imagens. Dentre os principais elementos, o conceito de tempo e espaço se inscreve como potencialmente vivo nessas interações, por intermédio da descrição de práticas, sensações e emoções vividas pelos personagens individual e socialmente. O que permite ao professor assegurar que, no enredo, estejam presentes as várias vozes, vivências sociais e rememorações esclarecedoras que compõem temporalidades na trama do enredo desenvolvido pelo autor. Aí está, como se entende, "a possibilidade do encontro com a historicidade" (Hartog, apud Guimarães, 2006, p.46).

Por meio desse "encontro" - mais do que uma descrição da imagem ou uma leitura de sua manifestação verbal - procura-se estabelecer uma espécie de reconhecimento dos sujeitos e suas ações, adentrar o espaço e verificar as temporalidades, por vezes obscurecidas pela ênfase nos aspectos lineares da narrativa literária. Espera-se assim que o aluno perceba que seu conhecimento cotidiano é capaz de apreender a realidade social como mudança e que seu presente coexiste com marcas do passado.

Em virtude da complexidade que tal proposta envolve - a organização pedagógica dedicada ao esforço de reflexão acerca dos fenômenos que 
compõem a compreensão da realidade social -, o cotidiano é a escala de análise privilegiada para uma apropriação dos conceitos que fundamentam a leitura temporal da prática social. Isso implica lidar com linguagens, narrativas e imagens que ajudem a entender no cotidiano a produção e a construção social da multiplicidade temporal explícita no enredo do texto.

Publicado em 1986, o livro Em volta do quarteirão é um exemplo de texto cujo sentido se constituiu pela interação de linguagens. No cenário aparecem: o pasteleiro, o jardineiro, o mecânico, o sapateiro, o amolador de facas, o encanador, o porteiro, o pipoqueiro, o carteiro, o quitandeiro, o fotógrafo, a sorveteria Tropical, a pichação e o guarda-noturno como personagens que compõem o tempo e o local do processo narrativo, delimitando-se assim um espaço urbano e aproximando-o do leitor contemporâneo. Ou seja, os personagens são retirados de situações reconhecidas no cotidiano infantil e a ilustração remete o olhar da criança para seus fazeres, de modo a abrir possibilidades para se trabalhar com as temporalidades presentes em suas vidas.

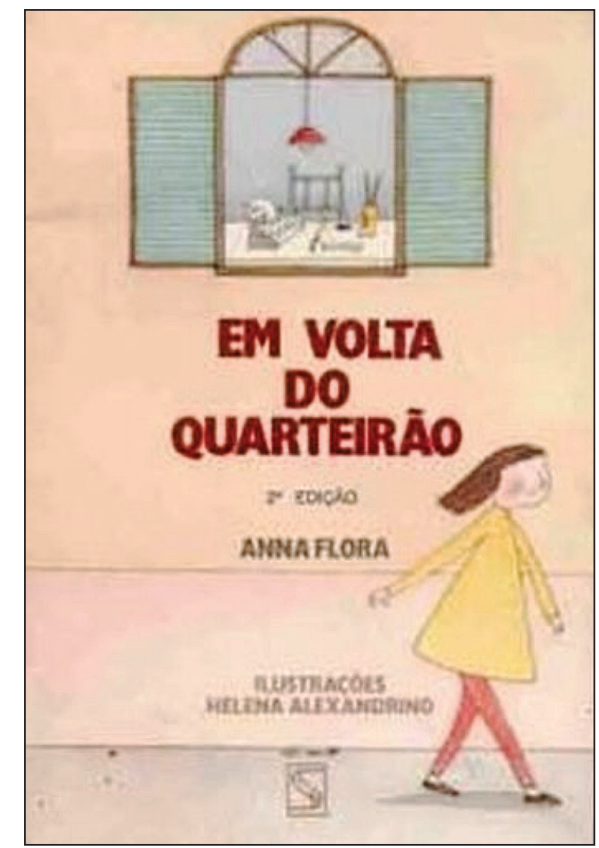

Figura 1 - Capa do livro Em volta do Quarteirão, publicado em 1986. 
Recorrendo a ilustração e versos, Em volta do quarteirão apresenta a menina da capa, que observa e dialoga com o imaginário coletivo de uma infância vivida em cenário urbano. O livro é composto por uma narrativa que apresenta poemas, em sua maioria rimados, sobre personagens que atuam na comunidade por meio de seus trabalhos e que são vistas cotidianamente no quarteirão. As ilustrações representam a vivência desses personagens. Por intermédio do porteiro, do mecânico, do sorveteiro, do sapateiro, do pasteleiro, do pipoqueiro, entre outros, o livro ilustra um cenário correspondente a um espaço que tem a menina (anônima) como protagonista. A circulação de pessoas possibilita certa convivência social, figurando assim alguns momentos da vida de uma cidade que, nas ilustrações, é mostrada de um ponto de vista que abrange tanto seu exterior (espaço público) quanto seu interior (as casas, vistas através das janelas).

A análise sociocultural do comportamento e das atitudes dos atores é realizada pela garota, que passeia pelo quarteirão observando calmamente o espaço e as sociabilidades nele vividas. Sua trajetória como observadora revela aspectos semelhantes aos da vida da autora, Anna Flora de Camargo Coelho, que, paulistana de nascimento (11 de julho de 1959), passou sua infância na Vila Madalena e em Pinheiros, lugares a cuja vida cotidiana seus livros infantis e infantojuvenis sempre remetem, realizando ademais um contraponto com suas vivências em bairros cheios de casas e cortiços. Como se sabe, trata-se de um cenário que, com o tempo, foi se transformando até que se tornasse um bairro de classe média.

O fato de que Os Argonautas, da mesma autora, tenha sido escrito precisamente nesse momento de mudança reafirma essa perspectiva. Poderíamos falar assim em literatura sobre a Vila Madalena no período da campanha da anistia:

Eu vou na Mitologia Grega e misturo com o mito dos argonautas com a história da Vila Madalena e a campanha pela anistia que foi nos anos 70. Principalmente, porque a Vila abrigou uns jornalistas importantes, porque eram os jornais que combatiam a ditadura e eram uns jornalistas que eram muito perseguidos pelo DOPS, pela polícia. Então tinham vários jornais que a sede era na Vila Madalena. (Coelho, 2008) 
A infância de Anna Flora é representada também em outras obras literárias concebidas para crianças que tratam do cotidiano citadino. De forma geral, encontram-se em seus escritos questionamentos sobre nós, seres históricos e urbanos. Afinal, quem de nós nunca cultivou algum tipo de sentimento por determinada rua, bairro, quarteirão? Pelo lugar onde nascemos, crescemos, brincamos, aprendemos? A rua, esse espaço de sociabilidades impregnado de alegrias, tristeza, solidão, temporalidades... Segundo ela, muitos de seus personagens são pessoas que viveram na Vila Madalena:

Tinha o louco do bairro. Era um guardinha que comandava um trânsito invisível e todos os moleques corriam do guardinha louco. Ele vinha muito quando tinha campeonato de futebol, e ficava apitando o jogo. Ele tinha um apito e ele apitava tudo: o trânsito, o jogo. Às vezes ele queria comandar o tráfego, porque não tinha tanto trânsito na Teodoro. Então às vezes ele ficava na Teodoro dando uma de guarda. O apelido dele era "guardinha louco" e a gente corria dele, a gente chamava: "guardinha louco" e quando ele vinha a gente corria. Aí eu fiz "O Louco do Bairro" que era sobre ele. E tinha o Gino Meneghetti, o ladrão de telhado. Mas quem me falava mais desse ladrão de telhado era o meu avô. (Coelho, 2008)

No livro em questão, o repertório ilustrativo, dedicado sobretudo aos personagens, é extenso. Tratando desse assunto a autora afirma que a ilustração é de suma importância na linguagem infantil, já que a criança começa a ler pelas figuras, o que faz com que a ilustração seja mais necessária quanto mais novo é o leitor concebido pela história. ${ }^{1} \mathrm{Uma}$ vez que os personagens aparecem relacionados a situações de trabalho, seus fazeres e locais de atuação também são representados por ilustrações - desenhos em preto e branco - que enfatizam as relações sociais e procuram explicam a realidade das ruas, do quarteirão.

Mas em que medida essa vivência da autora se liga à sua representação e leitura da história do lugar?

Escritora do espaço urbano, Anna Flora focaliza basicamente o significado, as motivações e os meios pelos quais a ação coletiva se realiza no espaço urbano, que ela de fato vivenciou. Certos padrões, rituais da vivência urbana presentes na narrativa são por ela problematizados, a fim de que se encontre um sentido cultural e social para a existência de seus personagens. Frases como 
as seguintes compõem a narrativa: "Nem todo japonês é pasteleiro, mas todo pasteleiro é japonês, fazendo garapa e pastel à espera do freguês".

$\mathrm{Na}$ rua está a feira e nela as vivências culturais. $\mathrm{Na}$ calçada, de onde se vê o movimento local, encontram-se animais domésticos, mas na cena predomina a presença de crianças - que correm e brincam. Tal cenário está voltado, pedagogicamente, para a ordenação de sentidos por parte da criança. É ela quem deve compreender e organizar suas percepções sobre a vivência coletiva de um conjunto disperso de personagens e disposto de maneira a serem apreendidos por meio das imagens e da narrativa. Esses elementos adquirem sentidos em seu conjunto. São objetos, pessoas, animais, nomes, datas, eventos, situações, entre outros, que informam as ações humanas realizadas em espaços públicos e temporalidades diversas.

O foco é a rua, seus moradores e seus fazeres. Eles ganham vida nos lugares diversos do quarteirão, acarretando assim percepção de tempos também diversos, nos quais se encontram e desencontram os personagens com suas experiências de vida e seus sonhos.

Em que medida a autora estabelece relações entre passado e presente?

O tempo está presente na linguagem e nas atividades desenvolvidas pelos personagens. Eles esperam, recordam, ganham ou perdem tempo. É por meio dele que as histórias individuais se relacionam com as histórias coletivas, de interação com o passado e o presente.

O jardineiro subiu no pé de feijão

E o feijão subiu de preço

O jardineiro subiu pro alto

Nem deixou o endereço

Foi subindo, subindo

Virou ponto final

Deu de cara com um satélite russo, artificial

Nele um saco de feijão abaixo do preço normal ...

(Coelho, 1986, p.4)

O que acontece com o jardineiro? Existe temporalidade na metáfora?

A temporalidade cronológica do crescimento do "pé de feijão" confronta-se com uma temporalidade econômico-social, portanto, distinta, porém 
simultânea, que é o aumento do preço do feijão como produto comercial: ambos sobem. E o jardineiro sobe junto, numa metáfora que se poderia supor de ruptura político-social com suas convicções existenciais - "nem deixou o endereço" - que possivelmente permite-lhe, se não uma compreensão de certezas políticas, certamente o entendimento de que vale a pena discutir - o porquê da existência de "um saco de feijão abaixo do preço normal". O que estaria, em termos históricos, relacionando o satélite russo com a ideia de um preço normal do feijão? Existiria, nessa escrita, papéis atribuídos ao acontecimento referentes a um evento histórico específico? Qual seria?

A observação que a menina faz de Mário, o mecânico, anuncia as diferenças sociais presentes no contexto do bairro:

Mário, mecânico, não tem carro próprio

Conserta o dos outros

Com sabedoria o fio condutor

Do seu coração faz a ligação com a bateria....

(Coelho, 1986, p.6)

Embora não se apresente maiores detalhes da trama, há reconhecimento de uma identidade, a de Mário. Pela sua profissão nutre paixão, é o personagem que dá vida às coisas da vida! Trata-se então de uma identidade ou vínculo que ata outros personagens a diferentes convicções sobre os valores sociais percebidos pelo personagem anterior. Seu Mário, assim como o sapateiro, Nicola, estão diante de uma mesma realidade que produz identidades diversas. É possível empregar um vocabulário e conceitos históricos adequados para explicar tal diferença no modo de vida desses personagens?

Do lado de fora, na rua, a personagem principal observa o Senhor Nicola. Visto como bom velhinho, ele é representado pela paixão, mas também pela solidão de seu ofício. Solidão produzida em parte pela industrialização dos sapatos, em parte pelo tempo que passou:

Há vinte anos trabalho só

De companhia um pássaro numa gaiola

Com quem Seu Nicola às vezes conversa...

Por isso, a rua inteira comenta: 
"o sapateiro é bom mas lelé da cachola"

(Coelho, 1986, p.8)

Ocorrem, nessa história pessoal, local, situações de inserção em um contexto mais amplo da vida social? Ora, no fundo da sapataria, fotografias, peças e objetos de seu ofício revelam a passagem do tempo. Vinte anos, mas ali estão representados muitos anos a mais de história. $\mathrm{O}$ cenário possibilita a reflexão sobre a importância dos objetos como fonte, enunciadores da vida de seu Nicola em mudança. Nesse cenário, vê-se que o tempo é indissociável do espaço, percebe-se a passagem do tempo por meio das mudanças do corpo e também nas mudanças ocorridas no espaço vivido.

As diferenças temporais percebidas e vivenciadas pelos personagens estruturam a narrativa e os nexos estabelecidos entre eles em suas percepções da vida em sociedade. O lugar, seus espaços de sociabilidades, propicia a construção de identidades que, por vezes, se distanciam ou se complementam, o que configura uma narrativa em que os sujeitos sociais se aproximam ou não do ponto de vista cultural.

Seu Nicola e seu Mário são assim, de certa forma, duas temporalidades presentes em um mesmo momento, em um mesmo lugar, captadas num lance do olhar da menina que tudo observa. Entrecruzam-se o jovem e o velho trabalhadores que, embora num mesmo tempo presente, percebem a formação do lugar em tempos vivenciados diferentes. Uma trama romanceada pelas paixões dedicada aos seus fazeres configura e atribui sentido ao descompasso temporal de seus anos de vida e à vivência no bairro.

Mas o tempo não é apenas percebido nesses termos. Novos personagens dão novos coloridos ao cenário. $\mathrm{O}$ amolador de facas está no canto da rua. $\mathrm{Na}$ paisagem, as pessoas que passam apressadas com suas maletas e outras entrevistas através da janela em seus trabalhos (costureira, professor de piano) observam Aparício a falar.

Amanhã vou afiar as ideias do prefeito

Quem sabe se desse jeito, ele tem mais respeito

Pelos que estão na praça, à procura de emprego?

(Coelho, 1986, p.10) 
Aparício tem "língua afiada"; por ele nada passa. Nas ruas do quarteirão ele se instala a esperar sua freguesia. Mas não só. Ele também observa os que vão sem trabalho e os que estão na praça sem ocupação. O tempo é movimento, ir e vir da multidão, é acelerado. No espaço central do bairro, Aparício representa o senhor urbano, já que dispõe de apurado gosto pela conversação e que é fascinado pelas sociabilidades menos restritas à domesticidade. Aparício tem temperamento alegre e se compadece diante da dor e da tristeza alheias. Seu caráter franco inclui também sensibilidade para os problemas sociais.

É possível relacionar sua presença no centro do bairro com a percepção do personagem da organização do trabalho - comércio, prestação de serviços - num lugar permeado das relações dos grupos em que convive?

No espaço urbano não existe, por certo, uma única percepção do tempo. É o que confirma a autora. Se o tempo aparece acelerado para Aparício, o tempo é percebido de forma diferente para o encanador, Seu Albano:
O encanador enganou a dor
Entrou pelo cano,
Filtrou a torneira do desengano
Entupiu o afeto escorrido do teto
O encanador se chama Albano

(Coelho, 1986, p.12)

No mesmo sentido, é percebido o porteiro. Sua visão de mundo foi construída do lado de dentro de uma guarita, onde o tempo demora passar, e ele passa seus dias preso atrás de "uma parede de vidro"! O tempo é representado pela metamorfose de Seu Pedro em peixe. Trata-se da metáfora usada para indicar o quanto eram mecânicas as funções que desempenhava. Na comparação, compreende-se que, embora cumprindo funções diferentes, Aparício e Pedro são representantes de grupos sociais que atuam no espaço urbano local, no mundo do trabalho, e são marcados pela maneira como essa sociedade entende e produz temporalidades na organização do tempo cronológico: seus ritmos de espera e solução de problemas...

A vivência do tempo carrega, nesses personagens, a ambiguidade entre um tempo que permanece e um que rompido pela socialização de seu drama e sua percepção individual frente às relações de trabalho, que se urbanizam e 
redefinem o espaço social. Esse, por sua vez, não se realiza de forma tranquila, harmoniosa, mas sim por conflitos e contradições. São registros que possibilitam problematizar as diferentes relações de trabalho e suas interferências culturais na vida dos sujeitos. O desemprego, como produto e produtor dessa relação, bate à porta de $\mathrm{S}$. Pedro trazendo mudanças em sua existência.

A coisa só piorou
Quando se alastrou uma fofoca sinistra:
Que diversos porteiros de outros prédios
Já estavam nadando em suas guaritas

Foi um deus nos acuda, um disse que disse

Despede, não despede com o síndico maldito

Já querendo fazer porteiro a escabeche

Mas é no coletivo que se explica o sentido da luta. A luta por uma

[vida melhor:

Chame seus colegas

Quebrem essas caixas e comecem a nadar

Virando todos peixes-porteiros

Tomando conta do fundo do mar!

(Coelho, 1986, p.14-15)

É possível apontar nessa história criada para um contexto escolar temas sobre a organização sindical trabalhista? A narrativa em questão permite reconhecer, nas atividades do comércio e dos trabalhos temporários, características da vida social capitalista?

Enquanto o coletivo se destacado no modo como se narra a vivência do porteiro, o carteiro, partindo de uma aventura própria à prática individualizada de seu cotidiano, torna-se sujeito público, testemunha o tempo da espera e o do inesperado. É, ao mesmo tempo, indivíduo e coletivo.

A saudade ele traz presa

Em um envelope branco

Mas às vezes, também carrega

conta de luz e de banco ...

(Coelho, 1986, p.16) 
O tempo está presente nos escritos - as cartas, o destinatário das encomendas. Por meio desse personagem, propicia-se o reconhecimento de que a vida social urbana está organizada pela cronologia do relógio, por horários de trabalho e por calendários. De que modo se pode explorar, por intermédio de seu cotidiano, diferentes formas de medição temporal?

O tempo do carteiro é descompassado na medida em que faz parte de seu trabalho transmitir notícias, boas e ruins. Se a carta chega atrasada, atrasada está a novidade, ansiosa está a alma que sente saudades. Noções relacionadas ao tempo como: datas, mudanças, sucessão, simultaneidade, entre outras, permitem lidar com o tempo social e o individual da esfera de um acontecimento. Na imagem, ele corre do cachorro, foge para o correio e conhece todas as ruas, do centro à periferia. É um tempo que se repete, permanece em suas ações para efetivar seu trabalho.

A presença do carteiro indica o reconhecimento, pela autora, de que o mundo sensível se constrói com o do leitor e na sua relação com o outro. Sujeitos, tempos, espaços, vivências diversas. O carteiro é um personagem cujo tempo é sempre relacionado ao espaço em que interpreta a vida social pela ótica da vida privada. Conhecer tais relações é fundamental para o ensino de História.

O quitandeiro é, em par com o carteiro, o personagem mais interessante. Seu dia de trabalho é também todo prenhe de continuidades. A ilustração enfatiza os objetos e seu cotidiano em meio às prateleiras, baleiros, sacos de feijão e outros grãos. Na ilustração é marcante a imagem do dono do comércio, com lápis atrás da orelha e cadernetas. Trata-se, como se vêm de um personagem que a tudo controla, inclusive o tempo.

Levanta às quatro da manhã

Meio dormindo, sonado

Vai direto pro CEASA

Fazer compra de atacado.

(Coelho, 1986, p.18)

$\mathrm{Na}$ vida do quitandeiro uma história de tempo longo:

A quitanda é uma ilha

Cercada de supermercados

Sobrevivendo teimosa

Tão solitária no bairro 
Seu dono é um espanhol
De olhar e fala mansa
Vindo da Andaluzia
Quando ainda era criança ...

(Coelho, 1986, p.19)

Depois da menção ao modo como as mercadorias são vendidas na quitanda, fica a questão: "será que a quitanda resiste num mundo onde só existe lugar para supermercado?” Um problema para o tempo presente está colocado. Pode-se indagar: "convivem, na urbanidade, relações com o espaço rural?". E o que dá vida ao passado?

A origem imigrante do quitandeiro e sua trajetória possibilitam pensar como ocorreu a ocupação aquele espaço? É possível trabalhar com noções de formação de povoados, vilas, bairros, a fim de explicar a solidão de que se reclama na narrativa?

O fotógrafo, seu Konrad, é, igualmente, um personagem de origem distante, assim como seu nome - distante do cotidiano de crianças brasileiras. Vindo da Áustria direto para o bairro é um sujeito que é visto como possuidor de objetos desconhecidos da maioria. Livros antigos e muitas fotografias dos lugares por onde passou - fotografias: memórias penduradas na parede de seu estúdio. Temos aqui assim uma atividade urbana que se realiza desde um tempo passado até o presente, mas que não surge aqui.

Veio sozinho para o Brasil

Só por gostar de aventura

Saiu voando no céu da Europa

Aterrizou na minha rua.

(Coelho, 1986, p.20)

A sua máquina, o seu estúdio
É sua Áustria
Recriada na esquina
E ele me olha com seus olhos azuis
E sempre me chama
De "meu menina".

(Coelho, 1986, p.21) 
Elementos da modernidade misturam-se com os aspectos culturais nos flashes de seu Konrad, que ainda cultiva saudade de sua terra natal. Tal personagem, além de conhecer a maneira como tais dispositivos - regidos pela tecnologia - funcionavam, também precisa relacionar-se com pessoas diversas. Pessoas de passagem, moradoras, seus colegas itinerantes ou possuidores de estúdios. É ele quem registra as transformações da cidade produzindo imagens de vários pontos do bairro. Seus registros trazem parte da história do lugar. Suas fotografias são documentos históricos. Quanta riqueza de material, tão apropriada para se tratar aqui da prática do historiador!

A "Sorveteria Tropical” é, já pelo seu nome, uma festa de sabores. O que significa "tropical"? A partir dessa questão, é possível lidar com aspectos culturais - costumes e alimentação - a fim de se compreender o acesso a uma variedade costumes alimentares, e suas heranças, próprias de um pais tropical? $\mathrm{O}$ nacional e o local se mesclam de muitas maneiras na rua. Do maracujá à seriguela, desfila a grande variedade de frutas que se produz de Norte a Sul no país.

Na ilustração, pessoas caminham em direção ao estabelecimento com expressões felizes, configurando um cenário tradicionalmente conhecido pelas crianças como um final de tarde de domingo. A ilustração parece querer suscitar uma relação de identidade entre a vida na rua de uma cidade de interior - onde as crianças ainda correm pelas ruas - e a sorveteria, que parece ocupar boa parte do quarteirão. Esse é um elemento que permite criar problematizações diversas, dentre elas, pensar se todos têm de fato acesso a todas as variedades alimentícias e se as crianças são todas realmente felizes, tal como demonstra a ilustração.

Outro elemento cultural que não poderia faltar nessa paisagem é a pichação. “Ei, moleque vá sujar sua parede!”. Os “moleques” são personagens Pablo e Pedro - que surgem no cenário urbano representando a difusão de linguagens tipicamente citadinas, a fim de indicar que mudanças na rua e na vida social estão acontecendo. Se, para alguns, pichar é sujar, para outros não.

\footnotetext{
"Não precisa se zangar"

- disse Pedro magoado -

"seu muro ficou mais bonito

Depois que ele foi pichado!”

"Proponho uma troca:

Eu pinto e você picha"

"Eu não!" - disse Pablo
} 
Morrendo de vontade

"sou um cara de respeito

Não tenho mais idade!"

(Coelho, 1986, p.25)

O desenrolar de tais mudanças é percebido no personagem Pablo. Nesse espaço de relações sociais - a rua - o tempo produz novos comportamentos que certamente serão questionados, tendo por princípio os costumes anteriores. Mas o fato é que novos comportamentos sociais produzem novos cenários na vida urbana. O que permitiria problematizar a vida cultural dos grupos que convivem no espaço local, identificar meios de comunicação, hábitos que permanecem ou que surgem.

Todas essas observações vividas pela menina, personagem central do livro, servirão para finalizar sua aventura pelo quarteirão. Ela aparece, em ilustração final, sentada e escrevendo em seu quarto, numa clara mensagem de que ler os espaços sociais produz conhecimento.

As representações da vida cotidiana que são expressas no livro de Anna Flora permitem ao leitor construir um olhar crítico para o espaço urbano. Ao mesmo tempo, possibilita trabalhar vários aspectos do tempo histórico: as sequências cronológicas observadas pela personagem principal; as formas como os demais personagens lidam com o tempo social em suas atividades; a duração temporal e suas percepções nas ilustrações; diferenças e semelhanças entre os personagens no uso do tempo e, fundamentalmente, como as crianças dos anos iniciais estão percebendo a temporalidade por meio da Literatura Infantil. Ou seja, permite ao professor reconhecer se elas conseguem notar que o tempo está presente nas ações e palavras dos personagens e que, certamente, tais personagens estão realizando essas ações em espaços específicos.

\section{CONSIDERAÇÕES FINAIS}

Os conceitos de tempo e espaço estão na base da aprendizagem da História escolar. Dificuldades no trato pedagógico com esses conceitos têm sido testemunhadas por professores do ensino fundamental e relatadas em pesquisas sobre o ensino dessa disciplina. No mesmo sentido, dialogar com o tempo presente tem propiciado discussões sobre como realizar um trabalho que 
signifique o saber histórico na prática de ensino, principalmente durante os anos iniciais do ensino fundamental.

Este artigo procurou apresentar um esforço de análise da Literatura Infantil como forma de se tratar dos conceitos de tempo e espaço no curso de formação de professores. Ao lidar com a literatura, sinalizou para a perspectiva de que ela procura representar ações de sujeitos sociais em um espaço, por intermédio de situações criadas pelo autor em diferentes dimensões temporais. A hipótese, já anunciada em vários trabalhos sobre o ensino de História no Brasil, foi a de que o uso da Literatura Infantil possibilita, pelas linguagens que apresenta, estudar as representações temporais e espaciais presentes na narrativa.

Para compreender a realidade social, a criança necessita ordenar seu pensamento por intermédio do tempo e dos espaços em que os acontecimentos ocorrem. Ela deverá sempre perguntar: "quanto aconteceu?"; “onde aconteceu?".

Na Literatura Infantil apresentada estão explícitas relações espaciais e temporalidades que expressam uma narrativa capaz de ordenar os acontecimentos por meio da "volta" feita pela menina no quarteirão. Os personagens que ela focaliza aparecem em situações históricas (vivenciando sua forma de ser e existir no bairro) e em ilustrações e narrativa prenhes de tipologia temporal e percepção desses tempos sociais (cronológica, passado, objetos, funções etc.) que, por sua vez se relacionam com a linguagem temporal que interessa ao ensino de História.

A Literatura Infantil contemporânea permite despertar interesse pela leitura histórica (de conceitos históricos) que se pode realizar de textos literários. Em sendo um tipo particular de narrativa sobre as práticas sociais em espaços urbanos, é adequada também para se conduzir uma discussão importante sobre o tempo histórico por meio de ações e falas de personagens que são representados em ilustrações.

Entende-se que o tempo do relato literário não é marcado apenas pelo tempo cronológico ou do calendário, mas por acontecimentos da vida cotidiana dos personagens, que podem se dar: na vida de trabalho, nos conflitos entre gerações, nas memórias, nas diferenças culturais, nos problemas da vida urbana, entre outros. Na narrativa literária encontram-se os ecos das relações sociais que as crianças vivenciam e cujo sentido histórico escolar buscamos estabelecer.

\section{REFERÊNCIAS}

ABRAMOVICH, Fanny. Literatura infantil: gostosuras e bobices. 2.ed. São Paulo: Scipione, 1991.

ABUD, Kátia M.; SILVA, André C. de M.; ALVES, Ronaldo C. Ensino de História. São Paulo: Cengage Learning, 2010. 
ARROYO, Leonardo. Literatura infantil brasileira. São Paulo: Melhoramentos, 1968.

BENJAMIN, Walter. Passagens. Belo Horizonte: Ed. UFMG, 2006.

BLANCH, Joan P.; FERNÁNDEZ, Antoni S. La enseñanza y el aprendizaje del tiempo histórico en la educación primaria. Caderno Cedes, Campinas, v.30, n.82, p.281-310, set./dez. 2010.

CAGNETI, Sueli de Souza. Livro que te quero livre. Rio de Janeiro: Nórdica, 1996.

CHARTIER, Roger. Debate: Literatura e História. Topoi, Rio de Janeiro, n.1, p.197-216, 1999.

COELHO, Anna Flora. Depoimentos. In: MUSEU DA PESSOA. Memórias da Literatura Infanto-Juvenil. 19 jun. 2008. Disponível em: http://www.museudapessoa.net/pt/ conteudo/historia/filosofia-para-criancas-49424; Acesso em: 14 jan. 2016.

GUIMARÃES, Manoel L. Salgado. Escrever a história, domesticar o passado. In: LOPES, Antonio H.: VELLOSO, Monica P.; PESAVENTO, Sandra J. História e Linguagens: texto, imagem, oralidade e representações. Rio de Janeiro: 7 Letras, 2006. . Em volta do quarteirão. São Paulo: Salamandra, 1986.

LAJOLO, Marisa; ZILBERMAN, Regina. Literatura infantil brasileira: história e histórias. 4.ed. São Paulo: Ática, 1988.

MEIRELES, Cecília. Problemas da Literatura Infantil. São Paulo, Summus, 1979.

MORTATTI, Maria do Rosário Longo. Na história do ensino da literatura no Brasil: problemas e possibilidades para o século XXI. Educar em Revista, Curitiba: Ed. UFPR, n.52, p.23-43, abr./jun. 2014.

MUSEU DA PESSOA. Memórias da Literatura Infanto-Juvenil. 19 jun. 2008. Disponível em: http://www.museudapessoa.net/pt/conteudo/historia/filosofia-para-criancas-49424.

OLIVEIRA, Sandra Regina F. de; MIRANDA, Sonia Regina. Por que refletir sobre o que significa educar para a compreensão do tempo? Caderno Cedes, Campinas, v.30, n.82, p.273-280, set./dez. 2010.

PESAVENTO, Sandra J. História \& História Cultural. 2.ed. Belo Horizonte: Autêntica, 2005.

ZAMBONI; Ernesta; FONSECA, Selva G. Contribuições da literatura infantil para a aprendizagem de noções do tempo histórico: leituras e indagações. Cadernos Cedes, Campinas, v.30, n.82, p.339-353, set./dez. 2010.

\section{NOTA}

${ }^{1}$ Segundo a autora, à medida em que se vai dominando mais a linguagem escrita, as ilustrações vão diminuindo.

Artigo recebido em 21 de setembro de 2015. Aprovado em 29 de dezembro de 2015. 